\title{
Gestão democrática do ensino público: as regras do jogo no campo educacional
}

MARILDA PASQUAL SCHNEIDER

SIMONE FLACH

MARCELO MOCARZEL

SABRINA MOEHLECKE

[...] não basta que o Estado abrigue uma Assembléia (sic), onde se reúnam todos os membros da classe exploradora ou os seus delegados para que haja democracia. Se tal Assembléia (sic) não for capaz de intervir efetivamente no processo decisório, e se estiver reduzida ao desempenho de um papel decorativo, a forma assumida pelo Estado não é a democrática. (SAES, 1987, p. 23)

No atual estágio do capitalismo, os processos democráticos, vinculados a diferentes perspectivas teóricas, encontram-se sob risco em todo o mundo. Não é sem sentido que a garantia de participação das massas nas decisões políticas se torna algo a ser perseguido e se transforma em pressuposto de enfrentamento às práticas autoritárias e conservadoras que insistem em se alastrar nos encaminhamentos políticos de diversos países. Mesmo os de longa tradição democrática enfrentam um avanço conservador que furta conquistas históricas sob a insígnia de proteção de seu povo e de seus valores considerados universais.

O Brasil, enquanto país de origem oligárquica e escravocrata, também se insere nesse contexto, principalmente em razão de que foi marcado por práticas ditatoriais em diferentes momentos de sua história. Tais práticas restringiram a vivência ampla da democracia pelo povo brasileiro, a qual, mesmo no século XXI, ainda limita a participação popular nos processos decisórios em diversas áreas.

Em que pese tais heranças sociais, culturais e políticas marcarem a compreensão sobre participação e democracia, a reabertura política ocorrida em meados dos anos de 1980 pode ser considerada como um grande marco para a retomada democrática no país e, consequentemente, para o entendimento acerca de como a população detém o poder sobre as discussões e decisões a respeito dos caminhos escolhidos para o desenvolvimento nacional nos mais variados setores. Nesse sentido, a Constituição Federal de 1988 reconheceu o amplo poder do povo nos rumos do país, reafirmando a democracia como eixo fundamental para a organização político-administrativa do país quando declarou que "todo poder emana do povo" (BRASIL, 1988). Esse pequeno trecho constitucional pode ser compreendido como resultado de inúmeras lutas históricas em defesa 
de oportunidade política para além do exercício do voto, na qual a vontade dos cidadãos é considerada para a definição de políticas públicas sociais, dentre as quais se insere a educação, visto que "é na esfera jurídico-política, ou seja, na esfera pública, que se dá a cidadania” (TONET, 1997, p. 87). Na esteira desse pensamento é possível afirmar que a cidadania existe vinculada ao exercício democrático ou, de outra forma, o processo democrático contribui para a formação do cidadão, mesmo que sob os limites do capitalismo e, por isso mesmo, os processos democráticos precisam ser perseguidos e valorizados, pois sem eles a cidadania resta truncada.

No campo da educação, o exercício democrático, enquanto prática e vivência formativa ampla, se expressa no princípio da gestão democrática do ensino público, tal qual denominado tanto no texto constitucional quanto em textos infraconstitucionais. Considerado inédito na história constitucional brasileira, o princípio da gestão democrática do ensino público foi introduzido na Constituição de 1988 influenciado, em boa medida, pelo movimento em defesa da democratização do país ocorrido concomitante à fase de esgotamento do regime militar.

De modo contraditório, no entanto, as reformas políticas e econômicas do final da década de 1980 e início dos anos de 1990 situaram-se tanto no contexto do movimento pela redemocratização política do país como de liberação e crescente privatização de serviços, inclusive da educação. As reformas educacionais também evidenciaram que o entendimento sobre gestão democrática não é unívoco, mas expressa diferentes posturas epistemológicas e ideologias. Portanto, ao ser entendido de diferentes formas, o princípio de gestão democrática do ensino pode abarcar diferentes práticas, as quais são validadas por diferentes perspectivas teóricas.

A partir dessa breve reflexão, a discussão que se busca estabelecer no presente Dossiê diz respeito à necessidade de se indagar sobre políticas e práticas de gestão democrática da educação básica tanto na América Latina quanto no Brasil. Todavia, o foco central das discussões está no princípio constitucional da gestão democrática do ensino público e sobre como tais políticas e práticas se inserem no processo de formação para a cidadania. Para tanto, o dossiê tem como foco principal o âmbito municipal, mas não excludente de outras práticas, e mira nas condições político-institucionais formalizadas em nível local a fim de responder à incumbência do município em traçar normas e patrocinar a democratização da gestão do ensino público na educação básica.

Para iniciar o debate, no texto intitulado Disputas por el derecho a la educación y la educación pública en América Latina: políticas, instituciones y sujetos en la gubernamentalidad neoliberal, Maria Helena Martínez e Vivana Isabel Seoane 
oferecem ao leitor reflexões sobre as democracias latino-americanas e como estas interferem nos processos de governabilidade inseridos em contexto neoliberal. $\mathrm{O}$ texto indica que as novas formas de mercantilização e privatização da educação pública e os novos modelos de gestão escolar contribuem para a reestruturação das relações de trabalho no sistema educativo.

Em seguida, o texto de Carlos André Sousa Dublante e Maria José Pires Barros Cardozo, Democratização da gestão do ensino público em Sistemas Municipais de Educaşão no Maranbão, apresenta a realidade maranhense enfocando os princípios da participação e da autonomia em Sistemas Municipais de Ensino daquele estado e como, a partir das previsões legais, algumas fragilidades locais se destacam.

Em seu artigo Gestão Democrática do Ensino Público em municípios pianienses: princípios, espaços e mecanismos de participação, Raimunda Maria da Cunha Ribeiro destaca que, a tanto a instituição de Sistemas Municipais de Ensino por meio legal, quanto a materialização da gestão democrática em municípios do Piauí, se encontram em processo.

Em Democracia e Gestão Democrática em Sistemas Municipais de Ensino: a realidade do estado do Paraná, Simone de Fátima Flach procura desvelar, a partir da análise dos fundamentos da democracia e sua relação com gestão democrática, a presencialidade do princípio constitucional nas políticas educacionais, indicando possibilidades e limites para sua efetivação em âmbito municipal.

Rosilene Lagares, Katia Cristina Ferreira Custódio Brito e Meire Lúcia Andrade da Silva realizam, no artigo Gestão da Educação em Sistemas, um debate a partir do exame do quadro normativo e de condições político-institucionais de gestão democrática em sistemas municipais de ensino do estado de Tocantins. Em seu estudo, as autoras destacam a presença de princípios/espaços/mecanismos essenciais à gestão democrática nos sistemas. Evenciam, contudo, o tensionamento entre o princípio e o método democráticos nos sistemas analisados.

No texto intitulado $A$ noção de gestão democrática e sua apropriação local: um estudo sobre a legislação de municípios gaúchos, Rosimar Serena Siqueira Esquinsani e Jarbas Dametto analisam os Planos Municipais de Educação de municípios riograndenses tendo como foco o desempenho, a eleição de diretores, e a instituição e manutenção de colegiados como indicadores de gestão democrática nas legislações municipais. No entanto, evidenciam a polissemia do termo democracia e algumas imprecisões da legislação tanto nacional quanto local.

Em Desafios da gestão na escola pública paulista: a percep̧̧ão do diretor ingressante, Lúcio Leite de Melo e Nonato Assis de Miranda exploram, por meio entrevistas com diretores de oito escolas públicas do estado de São Paulo, os desafios do primeiro ano do cargo de Diretor de Escola. Como resultados, destacam que há desafios pessoais, formativos e psicológicos que se fazem presentes a partir, 
principalmente, das questões burocráticas atribuídas aos gestores no exercício da função. Dadas essas atribuições, concluem que o diretor, muitas vezes, coloca os aspectos e demandas de natureza administrativa em primeiro plano, em detrimento do projeto pedagógico da escola.

$\mathrm{O}$ artigo Princípios e mecanismos de participação e decisão em sistemas municipais de ensino de Santa Catarina: uma leitura dos artefatos institucionais de democratização da gestão educacional, de autoria de Elton Luiz Nardi, Marilda Pasqual Schneider, Aline Bettiolo dos Santos e Durlei Maria Bernardon Rebelatto toma por referência resultados do subprojeto de uma pesquisa em rede, obtidos por meio de exame documental e de questionários tendo em vista destacar especificidades que caracterizam os sistemas municipais de ensino do referido estado e que demarcam contrastes em termos de participação e decisão. Os resultados do estudo realizado pelos autores apontam para a coexistência entre indícios de avanços e refreamentos à participação e decisão no âmbito dos municípios catarinenses.

Tendo como pano de fundo a mesma pesquisa em rede, Maria Lisboa Pfeil e Alzira Batalha Alcântara desenvolvem um estudo sobre as bases normativas institucionais da gestão democrática em Rio das Ostras, município que integra as baixadas litorâneas do estado do Rio de Janeiro. Sob o título Gestão democrática do ensino público em Rio das Ostras (RJ): avanços e retrocessos, o artigo destaca o fato de que, mesmo estando prevista na Lei Orgânica do município a participação e a eleição de diretor como pontos centrais. Esse fato leva as autoras a concluir que, em Rio das Ostras, houve um enfraquecimento da gestão democrática, sobretudo nos mecanismos que promovem a participação.

Para concluir este Dossiê, as autoras Daniela Mercedes Wagner e Maria Rosa Carbonari destacam que, nos países latino-americanos, o processo de democratização, desde a educação básica até a superior, vem sofrendo refreamento. No artigo Risieri Frondizi y Alberto Taquini (b): trayectorias y experticias dedicadas a transformar la universidad argentina de mediados del siglo XX, as autoras procuram enfatizar, contudo, esforços empreendidos na Argentina no sentido de mudar esta situação. Nesta direção, reconhecem os intelectuais Risieri Frondizi e Alberto Taquini (h) como sujeitos que, a partir de suas trajetórias pessoais, contribuíram para transformar a universidade argentina em meados do século XX.

O conjunto de textos que compõem este dossiê reflete, em certa medida, a amplitude do debate acadêmico-científico em torno de um tema atual e, ainda, emergente, bem como à possibilidade de qualificação desse debate considerando medidas concretas operadas em sistemas de ensino, seja no domínio das regras do jogo democrático, seja no domínio das práticas deste jogo. 


\section{OUTRAS TEMÁTICAS}

Dentro deste número, há ainda artigos submetidos em fluxo contínuo à RBPAE, bem como uma pesquisa encomendada para a Seção Especial. Tais trabalhos enriquecem a edição, ampliando as fronteiras da divulgação científica e da reflexão acerca da gestão e das políticas educacionais.

Os autores Tauã Carvalho de Assis e Maria da Glória Gohn debatem a relação entre educação e participação a partir da análise de periódicos. O artigo Educaşão e participação: uma investigação das perspectivas teóricas brasileiras traz um consistente levantamento de três importantes periódicos da área, apontando as diferentes perspectivas teóricas sobre participação sociopolítica que podem ser encontradas nos trabalhos de pesquisa.

Em Tendências de precarização do ensino superiorprivado no Brasil, Carlos Eduardo Bielschowsky analisa, com base nos microdados do INEP, as consequências da concentração de matrículas no ensino superior em 10 grandes grupos privados, responsáveis por 48,1\% das matrículas em 2018. Ao analisar as instituições a partir dos conceitos do Enade, evasão e outros critérios, traz um importante panorama sobre como a oligopolização pode interferir na qualidade da educação superior.

Rafael Bastos Costa de Oliveira, Virgínia Cecília da Rocha Louzada e Paulo David de Jesus Tostes dos Santos debatem as dimensão que a participação política dos estudantes têm na gestão da escola. Em Gestão democrática da educação, participação política e eleição de diretores: uma análise a partir da experiência das ocupações de escolas no Rio de Janeiro, os autores analisam a importância das ocupações ocorridas em 2016, no Rio de Janeiro, para as experiências dos estudantes e das comunidades escolares.

Ao analisar as escolhas discursivas do Grupo Estácio, Victor Laus-Gomes e Renata Andreoni realizam uma interpretação da postura da instituição de ensino dentro de uma perspectiva de mercantilização da educação superior. O artigo Uma perspectiva sistêmico-discursiva sobre a mercantilização e a estratégia de gestão do ensino superior traz uma importante análise das mudanças nas relações, agora mercantilizadas e com uma semântica própria vinculada à comunicação corporativa.

A pesquisa REUNI e seus impactos nas Instituições Federais de Educação Superior (IFES): uma análise da admissão de docentes de 2007 a 2017 faz uma abordagem sobre os dados oficiais do censo da educação superior dos anos de duração do programa, traçando um paralelo com a literatura publicada sobre o tema. O estudo, de autoria de Roberto de Souza Salles, Eduardo Faernstein, Mario Roberto Dal Poz e Pablo Silva Machado Bispo dos Santos analisa instituições de todas as regiões do país, com vistas a correlacionar o indicador escolhido com o desenvolvimento das diretrizes do programa. 
Cristiane Gularte Quintana e Dione Iara Silveira Kitzmann traçam um importante panorama das políticas de educação ambiental. O artigo Políticas públicas na educação ambiental e as mudanças climáticas se baseia em referências documentais, pelas quais são analisadas as interações entre seis políticas públicas ligadas a estes temas, abrangendo uma escala temporal de vinte anos.

$\mathrm{Na}$ Seção Especial, a pesquisa encomendada à pesquisadora Maria de Lourdes Fávero traz um relato sobre um dos mais profícuos grupos de pesquisa da educação brasileira. $\mathrm{O}$ artigo apresenta a experiência da construção coletiva do PROEDES, na Faculdade de Educação da Universidade Federal do Rio de Janeiro, no período de 1987 a 2009. Em O PROEDES - Programa de Estudos e Documentação Educaşão e Sociedade: origens e desenvolvimento, há uma rica reconstrução dos principais temas, estágios de pesquisa e componentes desse centro de memória e pesquisa da história e política educacional.

Convidamos leitores, autores e interessados a ler os textos deste volume, de modo a construirmos novas e outras possibilidades de intepretação e problematização sobre o tema da gestão democrática e de tantas outras questões atinentes à política e gestão da educação.

\section{REFERENNCIAS}

BRASIL. Constituição da República Federativa do Brasil. Brasília, DF: Senado, 1988.

SAES, D. Democracia. São Paulo: Ática, 1987.

TONET. I. Democracia ou Liberdade? Maceió: Edufal. 1997. 